\title{
Correction to: Incidence of giant cell arteritis in Western Norway 1972-2012: a retrospective cohort study
}

\author{
L. K. Brekke ${ }^{1,2,3,6^{*}}$, A. P. Diamantopoulos ${ }^{4}$, B.-T. Fevang ${ }^{2,3}$, J. Aßmus ${ }^{5}$, E. Esperø ${ }^{1}$ and C. G. Gjesda2 ${ }^{2,3}$
}

\section{Correction to: Arthritis Res Ther (2017) 19:278 \\ https://doi.org/10.1186/s13075-017-1479-6}

Following publication of the original article [1], the authors reported an error. The incorrect sex-specific incidences of GCA were published. The correct mean annual cumulative incidence was 22.0 (95\% CI 20.6-23.5) for women and 10.5 (95\% CI 9.5-11.5) for men; $p$-value $<0.001$ unaffected by the error. Revised versions of Fig. 2 and Table 2 are provided in this correction. Additionally, in the results section (page 4, first section) we report results of a sub-analysis of an extended cohort $(n=881)$. The correct annual cumulative incidence for women in this group was 24.1 and for men 11.6.

\section{Author details \\ ${ }^{1}$ Hospital for Rheumatic Diseases, Haugesund, Norway. ${ }^{2}$ Department of Clinical Science, University of Bergen, Bergen, Norway. ${ }^{3}$ Bergen Group of Epidemiology and Biomarkers in Rheumatic Disease (BEaBIRD), Department of Rheumatology, Haukeland University Hospital, Bergen, Norway. ${ }^{4}$ Martina Hansens Hospital, Bærum, Norway. ${ }^{5}$ Centre for Clinical Research, Haukeland University Hospital, Bergen, Norway. ${ }^{6}$ Hospital for Rheumatic Diseases \\ (HSRAS), PB 2175, 5504 Haugesund, Norway.}

Received: 19 November 2018 Accepted: 28 November 2018

Published online: 07 December 2018

\section{Reference}

1. Brekke LK, et al. Incidence of giant cell arteritis in Western Norway

1972-2012: a retrospective cohort study. Arthritis Res Ther. 2017;19:278.

https://doi.org/10.1186/s13075-017-1479-6.

\footnotetext{
*Correspondence: lene.kristin.brekke@hsr.as

${ }^{1}$ Hospital for Rheumatic Diseases, Haugesund, Norway

${ }^{2}$ Department of Clinical Science, University of Bergen, Bergen, Norway
} 


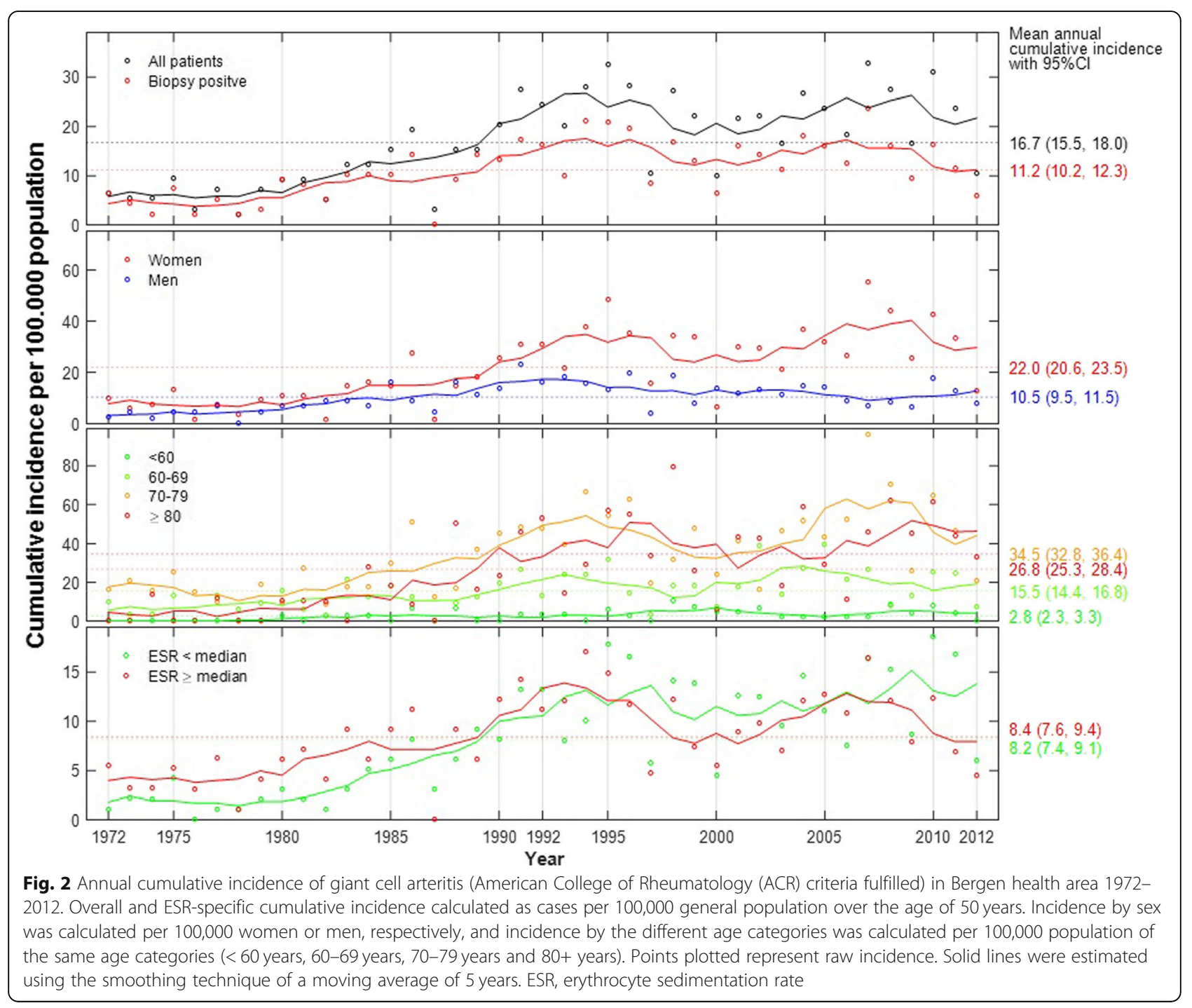


Table 2 The incidence of giant cell arteritis (GCA) in Bergen health area 1972-2012

a Mean annual cumulative incidence

$$
\text { All time }
$$

Cumulative incidence

All patients

16.7

Sex

Female 22.0

Male

$$
10.5
$$

Age, years

$\begin{array}{ll}<60 & 2.8 \\ 60-69 & 15.5 \\ 70-79 & 34.5 \\ 80+ & 26.8\end{array}$

$\mathrm{ESR}, \mathrm{mm} / \mathrm{hr}$

$$
\begin{aligned}
& E S R<85 \\
& E S R>85
\end{aligned}
$$$$
8.2
$$

b Relative risk (RR) according to time, sex, age and ESR

$$
\text { 1972-1992 }
$$

$\mathrm{RR}$

\section{Unadjusted}

Sex

$$
\begin{array}{ll}
\text { Time (years) } & 1.1 \\
\text { Sex (Male vs. Female) } & 0.6
\end{array}
$$

7.2

$70-79$ vs. $<60$

$$
15.4
$$

$80+$ vs. $<60$

9.5

ESR

$\begin{array}{ll}\text { Time (years) } & 1.1 \\ \text { ESR (>median vs. <median) } & 1.4\end{array}$

$$
\text { Time (years) }
$$

$$
\text { 1972-1992 }
$$

$95 \% \mathrm{Cl}$

$(15.5,18.0)$

Cumulative incidence

$$
11.2
$$

$(20.6,23.5) \quad 13.3$

$(9.5,11.5) \quad 8.6$

$\begin{array}{ll}(2.3,3.3) & 1.5 \\ (14.4,16.8) & 10.9 \\ (32.8,36.4) & 23.4 \\ (25.3,28.4) & 14.3\end{array}$

$(7.3,9.1)$

4.5

$(7.6,9.3)$

6.6

95\% Cl p-value

$(1.1,1.1) \quad<0.001$

$(1.1,1.1) \quad<0.001$

$(0.5,0.8)<0.001$

$(1.1,1.1)<0.001$

$(5.1,10.6) \quad<0.001$

$(11.0,22.5)<0.001$

$(6.7,13.9)<0.001$

$(1.1,1.1) \quad<0.001$

$(1.1,1.9)$

0.006
1993-2012

Cumulative incidence

$95 \% \mathrm{Cl}$

$(9.8,12.7) \quad 22.5$

$(20.5,24.7)$

$(11.8,14.9) \quad 31.2$

$(7.4,9.9) \quad 12.4$

$(28.8,33.7)$

$(10.9,14.0)$

$(1.0,2.1) \quad 4.1$

$(3.3,5.0)$

$(9.6,12.4) \quad 20.3$

$(18.4,22.4)$

$(21.4,25.6) \quad 46.2$

$(43.3,49.2)$

$(12.8,16.0) \quad 39.9$

$(37.2,42.7)$

$(3.7,5.5) \quad 12.0$

$(10.6,13.6)$

$(5.5,7.7) \quad 10.4$

$(9.0,11.8)$

1993-2012

RR $\quad 95 \% \mathrm{Cl} \quad$-value

$\begin{array}{lll}1.0 & (1.0,1.0) & 0.543\end{array}$

$1.0 \quad(1.0,1.0) \quad 0.462$

$0.4 \quad(0.3,0.5) \quad<0.001$

$1.0 \quad(1.0,1.0)$

$\begin{array}{lll}5.0 & (3.9,6.4)<0.001\end{array}$

$11.3 \quad(9.1,14.3) \quad<0.001$

$\begin{array}{lll}9.8 & (7.8,12.4) & <0.001\end{array}$

Overall and ESR-specific cumulative incidence reported as cases per 100,000 background population over the age of 50 years. Incidence for sex reported per 100,000 women or men respectively, and incidence for the different age categories reported per 100,000 population of the same age categories $(<60$ years, 60-69 years, 70-79 years and 80+ years). Relative risk calculated according to Poisson regression models for the two timeperiods 1972-1992 and 1993-2012

ESR Erythrocyte sedimentation rate

$\mathrm{Cl}$ Confidence interval 